\title{
In memory of a great suburban surgeon LUCIANO CASCIOLA (1948-2021)
}

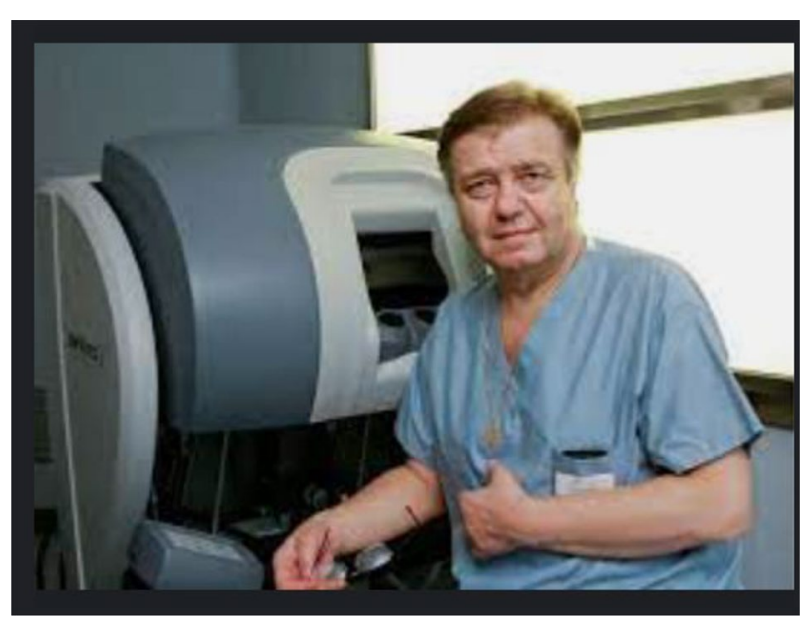

It may happen, in the time span of our lives, that someone born "in the middle of nowhere" may be specially gifted and always ahead of time.

Luciano Casciola was born in Trevi, a small charming village perched high up on a hill in Umbria, the region in the heart of Italy. He worked almost all his life in Spoleto, a small town too but somehow a cornerstone of human heritage in architecture, painting and lifestyle. He loved to ride his horse, wondering through the millennial paths and hills of his wonderful land. Does our home ground nurture us so as to help us find our way and fulfill our task on this earth? In the case of Luciano Casciola I can honestly say "Yes". He has marked the evolution of Italian surgery in the past thirty years: no other surgeon of our generation has done what he was able to do in his Spoleto.
He has enlightened all the fields of surgery with his intuitions and his charming and quiet way of operating. He was among the first surgeons to perform a successful laparoscopic cholecystectomy, splenectomy, gastric resection and colon resection as he was already, in the mid-1990s, a strong and motivated supporter of intracorporeal anastomosis for right hemicolectomy, a well-established procedure nowadays. Luciano was also an eminent vascular surgeon, one of the first in the world to apply minimally invasive surgery in this field. He introduced and developed the robotic approach to abdominal surgery and was among the first surgeons to perform a robotic major hepatectomy. He has codified miniinvasive liver surgery in a dedicated book by Springer.

Hundreds of surgeons have made their pilgrimage to Spoleto to learn from his hands and hundreds of times he has gone to them to help them progress as surgeons. He has raised dozens of pupils, always gentle, always sympathetic, always being a good soul, always eager to learn also from them. Today, those pupils enhance the reputation of Italian surgery.

With hundreds of farewell messages, Italian surgeons bow in front of Luciano Casciola who has donated his heart and his mind to the progress of our community for the sake of our patients. Like the great saints of Umbria, Luciano has traced the path and we want to thank him for having lived among us, unforgettably.

The Editors of UPDATES in Surgery.

Publisher's Note Springer Nature remains neutral with regard to jurisdictional claims in published maps and institutional affiliations. 